this decision. The moral dilemma for Debreu was to be fascinated by his mathematical experience of Nicolas Bourbaki, though he recoiled from it for its inadequacy towards the end of WWII. Instead of choosing for economics, he entered it by chance and remained a discreet economist throughout his entire intellectual life. In 1983, he faced the ambivalence of his intellectual life when he received the Noble Prize for "having proven the invisible hand of Adam Smith."

The thesis concludes pessimistically regarding the possibility of a significant economic science, but adds, in contrast, an optimistic note regarding the prospects of a post-epistemic culture in economic discourse.

\title{
JOYFUL ECONOMISTS: REMARKS ON THE HISTORY OF ECONOMICS AND PSYCHOLOGY FROM THE HAPPINESS STUDIES PERSPECTIVE
}

\section{JOSÉ M. EDWARDS}

Supervisor: Annie L. Cot

University: Economics Department, Université de Paris 1 Panthéon-Sorbonne

Date of Graduation: December 2009

Language: English

"Joyful Economists" explores the history of the relationship between economics and psychology from the viewpoint of the recent development of "the economics of happiness" (1974-2009). It positions itself in relationship to three particular accounts of the history of economics: the history of happiness in economics; the standard history of the relationship between economics and psychology; and the history of the economic use of survey data. It consists of three parts.

Part I: The Economics of Happiness presents the history of the subfield in two periods. Chapter 1: Economics for the Affluent, Happiness for the Satisfied (19741999) presents the first economic studies of happiness and claims that early economists of happiness were focused on the analysis of consumer well-being in affluent contexts. It shows that this research was less focused on resource availability than on the formation of consumer preferences. It proposes quite radical changes in consumer choice theory and welfare analysis by considering consumer behavior as being controlled by socio-economic environments (rather than being the revelation of internal preferences). Chapter 2: Making Happiness an Economic Subject (19992009) deals with the recent development of the subfield. It claims that this development has been strongly influenced by parallel developments in "hedonic psychology" and "behavioral economics," and shows that the economic analysis of happiness data has become intensive. Moreover, unlike early developments in the 
subfield, the recent economics of happiness is being presented as a complement, rather than an alternative, to the "revealed-preference framework that dominates the discipline of economics" (Clark et al. 2008, p. 136).

Parts II and III of the thesis take the history of the economics of happiness (as presented in Part I) as a viewpoint from which to explore, first, the history of the relationship between economics and experimental psychology, and then the history of the economic use of subjective data. There is, thus, an important change of perspective between Part I on one hand, and parts II and III on the other.

Part II: Bypassing Behavior Control revisits the history of the relationship between economics and experimental psychology. It does so by questioning two widespread views held by economists. The first view is that the ordinal revolution was a behaviorist move in economics: "A behaviorist movement arose in economics, as theorists attempted to free economics of all psychological elements. This movement contributed to the replacement of the older theory of cardinal utility, with the new notion of ordinal preferences" (Lewin 1996, p. 1295).

The second view is that psychology has been "in" or "out" of the development of consumer choice theory: "In simplified form, the standard story of consumer choice theory is that psychology came into economics during the neoclassical revolution of the 1870s, and remained in for the period of cardinal utility theory, but then was driven out during the ordinal and revealed preference revolutions" (Hands 2009, p. 2, emphasis added).

Chapter 3: Beyond Freedom and Dignity (From Behavior Control to the Economics of Affluence) challenges the first of these two accounts. It presents the historical origins of behavior-control research in psychology, and shows that while behaviorism had a strong influence in economics through the work of American institutionalists such as W.C. Mitchell, L.K. Frank, and M.A. Copeland (and through the economics of affluence as presented in Part I), it was far removed from the revealed-preference framework that came to dominate consumer choice theory. Chapter 4: The Economists' Psychologies maintains there have been different kinds of psychology involved in the historical development of consumer choice theory (such as psychophysical analysis, information-processing studies, adaptation-level theory, and behavioral-decision research). It is presented as an alternative to the standard history of the relationship between the two disciplines.

Part III: Subjective Quantification in Economics takes the history of the economics of happiness as a viewpoint from which to explore the history of the economic use of subjective data. Its principal aim is to enrich the current version of this history, which tends to reproduce the following statement:

Economists are so impressed by the confusions that might possibly result from questionnaires that they abandon them entirely, in favor of the confusion resulting from external observation. They are unthinkingly committed to the notion that only the externally observable behavior of economic actors is admissible evidence in arguments concerning economics (McCloskey 1983, p. 514, emphasis added).

The two chapters of Part III distinguish the use of subjective data as "scientific tools" from their use as "tools for government." Chapter 5: Subjective Quantification and Economic Theory discusses the program of behavioral economics as developed by George Katona at the Survey Research Center of the University of Michigan. This 
program was a source of vivid debates about the use of subjective data as "scientific tools." Chapter 6: Subjective Quantification and Economic Policy shows there has been an increase in the use of such data as "tools for government." It concludes by claiming that, indeed, the most recent developments in the economics of happiness are attempts to use happiness data in this way (i.e., the life satisfaction approach for valuing environmental goods). This fact supports the historiography that takes the emergence of new subfields (the economics of happiness in this particular case) as a viewpoint to explore the history of core parts of a discipline.

\section{REFERENCES}

Clark, A., P. Frijters, and M. A. Shields. 2008. "Relative Income, Happiness, and Utility: An Explanation for the Easterlin Paradox and Other Puzzles." Journal of Economic Literature 46 (1): 95-144.

Hands, D. W. 2010. "Economics, Psychology and the History of Consumer Choice Theory." Cambridge Journal of Economics 34 (4): 633-648.

Lewin, S. B. 1996. "Economics and Psychology: Lessons for Our Own Day from the Early Twentieth Century." Journal of Economic Literature 34 (3): 1293-1323.

McCloskey, D. N. 1983. "The Rhetoric of Economics." Journal of Economic Literature 21 (2): 481-517.

\section{AMERICAN ECONOMICS AT THE TURN OF THE $20^{\mathrm{TH}}$ CENTURY: THORSTEIN B. VEBLEN, ALFRED MARSHALL, AND THE METHODOLOGICAL FOUNDATIONS OF INSTITUTIONALISM}

\section{TIZIANA FORESTI*}

Supervisors: Prof. Malcolm Rutherford (University of Victoria BC, Canada) Prof. Luca Fiorito (University of Palermo, Italy)

University: Faculty of Economics, University of Florence, Italy

Date of Graduation: March 2009

Language: English

My dissertation provides a rereading of the rise of American institutionalism from the viewpoint of its endorsement and/or refusal of the analytical tools of the neoclassical economics of Alfred Marshall. As such, my research also illuminates the reception of Marshallian economics in the United States, a subject as yet almost entirely neglected in the scholarly literature.

*University of Pisa, email: ti.foresti@katamail.com 